\title{
Occupational Stress among School Teachers of Kashmir with Respect to their Age
}

\author{
Arshad Ali Bhat \\ Academic Counselor, Indira Gandhi National Open University, Delina Baramulla Jammu and Kashmir (193103)
}

\begin{abstract}
Age can be explained in the terms, that the individuals matured personality disposition related to the attainment of developmental tasks specific to each developmental phase and its influence on individual's perception of the situations as stressful or otherwise. The present study measured occupational stress among school teachers working in different schools of Kashmir India. In this research we used the Occupational stress index (O.S.I) developed by Srivastava and Singh (1983) were used to assess the level of occupational stress of the sample. The findings of study indicate that age group of teachers was important variable for the perception of occupational stress. Younger age teachers (20-30 years) perceived greater occupational stress than their counterparts in the middle age (30-40 years) and the old age groups (40-50 years). The study also found that the age found to be negatively correlated with occupational stress.
\end{abstract}

Keywords: Occupational stress, Teachers, Age

\section{Stress an Overview}

There is a widespread public perception that stress is an increasingly an important Issue and there is a large of studies .That describe rising levels of workplace in a range of countries. Stress is simply a fact of nature-forces from the outside world affecting the individual. The individual responds to stress in ways that affect the Individual as well as their environment. Hence, all living creatures are in a constant interchange with their surroundings (the ecosystem), both physically and behaviorally. This interplay of forces, or energy, is of course present in the relationships between all matter in the universe, whether it is living (animate) or not living (inanimate). However, there are critical differences in how different living creatures relate to their environment. These differences have far-reaching consequences for survival. Because of the overabundance of stress in our modern lives, we usually think of stress as a negative experience, but from a biological point of view, stress can be a neutral, negative, or positive experience._. "Stress is a concept borrowed from natural sciences by seyle in 1936. Hans Selye is regarded as the father of the modern concept of stress. He first popularized the word During 18th and 19th century stress was equated with force and strain exerted upon a material object or person which resists these forces and attempts to maintain its original state throughout 19th and 20th century .stress is a complex phenomena it is very subjective experience, what may be challenge for one will be a stressor for another it depends largely on background experiences temperament and environmental conditions .stress is a part of life and is generated by constantly changing situations that a person must face .The term "stress refers to an internal state which results from frustrating or unsatisfying conditions, a certain level of stress is unavoidable because of its complex nature. Stress has been studied for many years by researchers in psychology. The word " Stress" has been derived from the Latin word "stringer" which means to draw tight. The term was used to refer the hardship, strain, adversity or affection. Stress is an integral part of natural fabric of life. it refers both to the circumstances that place physical or psychological demands on an individual and to the emotional reactions, experiences in these situations. Selye in 1976 found that our bodies react to stress - like the stress of being ill - with a recognizable pattern of responses. There can be up to three phases that our resistance levels go through when we are exposed to a stressor. The first is the alarm phase. The body's resistance to physical damage drops for a short-time. This is so our bodies can prepare to cope with the stressor by using up available energy and normally protective stress hormones. Temporarily some of our defenses against physical damage drop so that our blood pressure increases, blood-sugar rises, muscle tension increases, we breathe faster and deeper and we get a surge of adrenaline-like substances to give us extra physical capabilities should we need them. If the stressor no longer exists the body returns to its normal level of resistance. However if the stressor persists, (we can't fight or flee from it or - and this goes beyond his original thinking we are unable to apply counteracting psychosocial resources) our level of resistance increases beyond normal, relaxed levels. Our bodies start to run in higher gear. High levels of stress hormones continue to help us cope with the stressor. This is appropriately called the resistance phase. If there is no relief the body can continue for days, weeks, even years until either the stressor is suddenly removed or because it is very energy-consuming our body collapses often with more dangerous and extreme physical reactions. They are the same as in the alarm phase only more intense and more relentless. It is here in this third or exhaustion phase that our health suffers or even death can occur. Our level of resistance to physical disorder, disease and psychological pressure is at its lowest. It is characterised by feelings of lethargy - an absence of energy and bodily resources to cope. The most likely physical and psychological signs and symptoms are the constitutional weak links discoverable in our personal histories and genetic inheritances.

\section{Occupational Stress}

Now a day people are living in an era of growing complexities and pressures where human constitution and capacities are being taxed severely. The stresses relating to job have become predominant feature of modern life, exerting for reaching effects on focal employee's behaviors 


\section{International Journal of Science and Research (IJSR) \\ ISSN (Online): 2319-7064}

Index Copernicus Value (2016): 79.57 | Impact Factor (2015): 6.391

and adjustments on as well as off-the-job. This is the reason that systematic studies of stress in organizational setting have increased dramatically over the past one decade. Recently, job stress has come into prominent work-related research topic. The psychologists and management scientists have different views about potential psychological and situational conditions or job related factors which cause job stress. The human body has a natural chemical response to a threat or demand, commonly known as the "flight or fight" reaction, which includes the release of adrenalin. Once the threat or demand is over the body can return to its natural state. Occupational stress can be defined as the harmful physical and emotional responses that occur when the requirements of the job do not match the capabilities, resources, needs of the worker. Job stress lead to poor health and even injury. The concept of occupational stress is often confused with challenge, but these concepts are not the same, challenge energizes us physiologically and physically and it motivates us to learn new skills and master our occupations when a challenge is met. The national institute for occupational safety \&Health (Niosh) defined occupational stress as'. "The harmful physical and emotional responses that occur when the requirements of the job do not match the capabilities, resources or needs of the worker". The orthodox approach to stress takes the view in a very simplified form that there are "stressors" in the work environment due to job characteristics which lead to" strain" for individuals. Occupational stress has been defined as employees mental state aroused by a job situation or a combination of job situations perceived as presenting excessive and divergent demands (Srivastava 1999).

Okebukola and jegede (1989), defined occupational stress as "a condition of mental and physical exertion brought about as a result of harassing events or dissatisfying elements or general features of the working environment". Berg (1990) conceptualizes teacher stress as a negative and potentially harmful to teacher's health. The key element in the definition is the teachers perception of threat based an the following three aspects of his job circumstances, 1. demands are being made on him,2.that he is unable to meet or has difficulty in meeting these demands,3.that feature to meet these demands threatens his mental and physical well being. Perhaps now, more than ever before, occupational stress poses a threat to the health of workers. Stress has long been associated with the onset of significant physical and mental health problems. In the organizational environment, stress has been implicated in the deterioration of performance efficiency by both managers and subordinates. When performance efficiency suffers the quality of the overall organizational environment and productivity deteriorates. As a result deterioration in organizational communication can be observed. A stress response will occur as a result of an individual's interaction with and reaction to the stressor" (Knotts, 1996). Taskrelated stress is directly related to the specific characteristics of the job itself. This type of stress involves role ambiguity, conflicting task demands, work overload or work under load, inadequate resource support, no provision for meaningful participation in decision-making, and insecurity, among others (Knotts, 1996). Physical demands of the workplace are another source to be considered. Environmental factors such as temperature variations, noise vibrations, and lighting may significantly lead to individual stress. For example, "extremes in lighting can cause stress, which often results in headaches and nervous tension" (Knotts, 1996). Role demands are external to the tasks associated with a job. This particular type of stress typically develops as a result of flawed organizational structures, ineffective organizational development, the inability of an individual to successfully pursue achievement goals within an organization, or some combination of all three. The individual's stress often results when his or her work role and responsibility has not been clearly defined (Knotts, 1996). The final source area of occupational stress relates to interpersonal demands. "Interpersonal stress at work is concerned with the demands that are placed on us in developing working relationships with other people in our organizations" (Knotts, 1996). Leadership style of headmasters and supervisors is often a source of stress for their employees. The result of stressors commonly associated with occupational stress tends to vary widely. Workers may simply resort to daydreaming or fantasizing. Alternatively, employees may react more actively by creating interpersonal and intra-organizational conflicts involving escalating levels of communication problems. Workers may also experience effects in their psychological and physical health. Psychological consequences may include anxiety, boredom, low selfesteem, forgetfulness, depression, anger, apathy, or worry. Physical consequences may include, but are certainly not limited to, headaches, diabetes, fatigue, hypertension, chest and back pain, ulcers, or even infectious diseases.

\section{Occupational stress among school teachers}

Dunham (1992) advocated that three main approaches could be used to understand the nature of stress in teaching. The first one is analogous to the "engineering" model of stress. There are external pressures exerted on teachers in schools, and teachers have limits to stress. In this approach, stress is a set of causes. The second approach is based on the "physiological" model, which focuses on the forms of reactions taken by teachers in response to these pressures. They may be emotional and bodily manifestations. The third one is the inter-actional approach that emphasizes the need to identify the sources of stress and the behaviour that they adopt to cope with these demands. Dunham (1992) has provided new insights by proposing a third emphasis on coping strategies that teachers can adopt to tackle stress problems. Kyriacou and Sutcliffe (1978a), who presented a model of teacher stress which conceptualized teacher stress as" a response syndrome mediated by an appraisal of threat to the teacher's self-esteem or well-being and by coping mechanisms activated to reduce the perceived threat". Dunham (1992) Explain stress as a process of behavioral, emotional, mental, and physical.

\subsection{Effects of occupational stress on teachers}

Based on the literature review, there appear three lines of research done on the effects of occupational stress on teachers: Dunham (1984) Presented the most frequent manifestations of teacher stress as: feeling of exhaustion, irritability, tension, and headache. He (1992) further identified four kinds of stress effects: (a) behavioral (e.g. 


\section{International Journal of Science and Research (IJSR) \\ ISSN (Online): 2319-7064}

Index Copernicus Value (2016): 79.57 | Impact Factor (2015): 6.391

heavy smoking, absenteeism, and turnover); (b) emotional (e.g. nervousness, anxiety, and depression); (c) mental (e.g. inability to concentrate); and (d) physical (e.g. headache and gastro-intestinal problems).Apparently, Dunham (1984, 1992) has reported well the common stress symptoms that might be manifested by stressed teachers.

\subsection{Causes of occupational stress}

Everyone agrees that occupational stress results from the interaction of the worker and the conditions of work. Views differ, however, on the importance of worker characteristics versus working conditions as the primary cause of occupational stress. These differing viewpoints are important because they suggest different ways to prevent stress at work. According to one school of thought, differences in individual characteristics such as personality and coping style is most important in predicting whether certain occupational conditions will result in stress, In other words, what is stressful for one person may not be a problem for someone else. This viewpoint leads to prevention strategies that focus on workers and ways to help them cope with demanding occupational conditions. Although the importance of individual differences cannot be ignored, scientific evidence suggests that certain working conditions are stressful to most people. The excessive workload demands and conflicting expectations. Such evidence argues for a greater emphasis on working conditions as the key source of occupational redesign as a primary prevention strategy. Job stress has been associated with poor mental and physical health. A useful model for understanding how the work environment affects individual health and well-being is provided by

Levi (1996) He describes the following components:

1. Stressors: These are aspects of the working environment that cause stress for the individual.

2. Appraisal: The way a stressor is appraised will vary between individuals depending on such things as personality, customs and attitudes.

3. Stress: Stress is produced when the stressor interacts with the individual's appraisal of it to induce emotional, behavioral and physiological reactions .Emotional reactions include, anxiety, depression, restlessness and fatigue. Behavioral reactions include increased smoking, overindulgence in food or drink and taking unnecessary risks. Physiological reactions include increased blood pressure, increased or irregular heartbeat, muscular tension and associated pain and heartburn.

4.Disease: The above reactions may result in suffering ,illness and death (e.g. through suicide, diseases of heart and blood vessels, or cancer).This sequence of events may be promoted or counteracted by interacting variables such as coping repertoire, social support, physical environmental and nutrition.

\section{Statement of the problem}

"Occupational Stress among School Teachers of Kashmir with Respect to their Age"

The objectives of this study were as follows: (a) To identify the sources of occupational stress viz, role overload, role ambiguity, role conflict, unreasonable group and political pressure, responsibility for person, under participation, powerlessness, poor peer relations, intrinsic impoverishment, low status, strenuous work conditions, unprofitability among government and private school teachers.

(b) The study also aims to compare the level of occupational stress among school teachers

\section{Hypothesis}

There is no significant difference of occupational stress in different age groups of school teachers.

\section{Method}

- Sample: This sample of the study comprised 120 teachers. Of the total of 120 subjects 45 were identified as young adults (20-30 years), 57 as early middle age (30-40 years) and 18 as late middle age (40-50 years). All the subjects completed the age range of 20-50 years were selected without any bias through a standard manner from the different schools of Kashmir.

- Tools: Tools for the collection of data it is quite necessary to adopt a systematic procedure. For every type of research, there is need of certain instruments to explore new fields. The instruments employed for the collection of data are called tools. Questionnaire addressed the area of occupational stress. Respondents also submitted their demographic factors such as age, sex, qualifications and school of type. Occupational stress index the questionnaire was constructed by Srivastava and Singh (1983). The questionnaire has 46 items, each to be rated on five point scale. Out of 46 items 28 are "true keyed" and 18 are "false-keyed". The items related almost all relevant components of job life which cause stress in some way or the other way.

- Data Analysis: Scoring was completed according to the directions in instrument user manual. Analysis procedures included generation of descriptive statistics to identify levels of occupational stress experienced by government and private school teachers or male and female teachers stepwise multiple regression to determine variables that predicted differences in levels of occupational stress. In cases where respondents did not answer a question, data were treated as missing values.

\section{Results}

\section{Occupational stress index overall scores}

Means and standard deviations of the scores obtained on occupational stress index is shown in table 1.Summary of ANOVA for Occupational stress index is displayed in table 2. It reflects that main effect of age was significant, $F(2,108)$ $=32.75, \mathrm{P}<.01$. Pattern of results indicate that younger age teachers perceived higher occupational stress $(M=137.53)$ as compared to middle age $(\mathrm{M}=121.86)$ and old age teachers $(M=116.67)$. Interaction effect age with sex was not significant, $\mathrm{F}(2,108)=.684, \mathrm{P}>.05$. Interaction effect of age with type of school was significant, $\mathrm{F}(2,108)=3.31, \mathrm{P}<05$. A close look on mean scores indicate that younger age private teachers showed higher occupational stress $(M=142.00)$ as compared to younger age Govt teachers $(M=131.42)$ and middle age Govt teachers perceived less occupational stress

\section{Volume 6 Issue 12, December 2017}




\section{International Journal of Science and Research (IJSR) \\ ISSN (Online): 2319-7064}

Index Copernicus Value (2016): 79.57 | Impact Factor (2015): 6.391

$(\mathrm{M}=121.58)$ as compared to middle age private teachers $(M=122.25)$ Mean scores also indicate that old age Govt and private teachers showed no difference $(\mathrm{M}=116.67)$, $(\mathrm{M}=167.67)$ respectively.

Table 1: Means and standard deviations of scores indicating occupational stress index.

\begin{tabular}{|c|c|c|}
\hline Age & Mean & Std. Deviation \\
\hline 20-30 years & 137.53 & 12.311 \\
\hline 30-40 years & 121.86 & 9.617 \\
\hline 40-50 years & 116.67 & 5.739 \\
\hline
\end{tabular}

Table 2: Summary of ANOVA performed on the scores for occupational stress index

\begin{tabular}{|c|c|c|c|c|}
\hline $\begin{array}{c}\text { Source of } \\
\text { variations }\end{array}$ & $\begin{array}{c}\text { Sum of } \\
\text { Squares }\end{array}$ & Df & $\begin{array}{c}\text { Mean } \\
\text { Square }\end{array}$ & F \\
\hline Age & 6563.448 & 2 & 3281.724 & $32.757 * *$ \\
\hline
\end{tabular}

** Significant at .01 level

\section{Discussion}

The present study was examining the level of occupational stress among teachers. Findings of study support that age was an important variable in the development of occupational stress. pattern of results indicate that younger age teachers experienced higher scores on occupational stress than middle age teachers and old age teachers According to Bothwick et al. (1982), that younger age teachers with few years of teaching experience might not be aware of the inevitable stress in teaching life and lacked proper coping in the state of perceived stress and feel insecure due to lack of experience. They also feel status incongruity, lack of support, lack of co-operation with their more experienced counterparts. Young teachers experiencing higher role overload, the young age teachers must have put one to ten years of service in their job which is relatively a short period they may be getting adjusted to their jobs as well as to demands and adjusts of young married life. Younger age teachers also perceived higher role ambiguity and political pressure which shows their intolerance of pressures which might create role ambiguity in their work. Younger age teachers were found to be more susceptible to conflict related stress. Younger age teacher's work as junior employees, due to that senior employees thrust the responsibility for the efficacy and productivity of many new assignments upon teachers. They produce more than the usual. The young teachers did not work properly in tense circumstances and did not complete assignments which are quite risky and complicated due to the low experience and maladjustments in these situations.

\section{References}

[1] Borg M.G \& Riding, R.J. (1991), Occupational stress and satisfaction in teaching, British Educational Research Journal, 17 pp.263-81

[2] Clark, E. (1980). An analysis of occupational stress factors as perceived by public School teachers. Unpublished doctoral dissertation, Auburn University.

[3] COOPER, C.L (1988) Living with stress. Harmonsworth: Penguin.

[4] Caplan, R.D., (1972), Organisational stress and individual strain: A social psychological study of risk factors in coronary heart disease among administrators, engineers and scientists, Dissertation Abstracts International, 32(11 B), 6706B

[5] Dunham, J. (1984). Stress in teaching. London: Croom Helm.

[6] Dunham, J. (1992). Stress in teaching (2nd ed.). London: Routledge

[7] Dickie, K.(1995). Stress and the college educator: A qualitative study. Unpublished M.Ed. thesis. Brock University, St. Catharines.

[8] Franch J. R. P., and R. D Caplan. 1972. Organizational Stress and Individual Strain.In The Failure of Success, A. J. Marrow, Ed. New York: AMACOM

[9] Kobasa S C (1979), Stressful life events, personality \& health, an inquiry into hardiness, journal of personality \& social psychology 37,1-11

[10] Kyriacou, C., \&Sutcliffe, J. (1979), Teacher stress and satisfaction, Educational Research, Vol. 21 pp.89-96

[11] Kyriacou, C., (1987), 'Teacher Stress \& Burnout: An International Review' in Educational Research 29(2)

[12] Knotts, T. (1996, July 8). Workplace stress doesn't have to kill you. Business Journal Serving Fresno \& the Central San Joaquin Valley, 322013. [EBSCOhost]. University of Phoenix Online Collection.

[13] Kahn, R. L. (1974). Conflict, Ambiguity and Overload: three Elements in the job stress. In A. Mclean (ed.), Occupational Stress Springfield, IL. Thomas, 47-61.

[14]Lazarus, R. S. (1991). Psychological stress in the workplace. In E. Perrewe (Ed.), Handbook of job stress [Special Issue]. Journal of Social Behavior and Personality, 6(7), 1-13.

[15] McClean A A (1980) Work stress M.A Addison Wasely

[16] Okebukola, P.A.\& Jegede, O. J. (1989), "Determinants of occupational stress among teachers in Nigeria", Educational Studies, Vol. 15 pp.23-36..

[17] Selye, H. (1956)The Stress of Life. McGraw-Hill, New York,

[18] Selye, H. (1981) Dealing with stress in a depressed economy. Spectrum 2, 3-12.

[19] Selye, H. (1974) Stress without distress. New York: NAL Penguin Inc

[20] Srivastava A K \& Singh A P (1981), Construction and standardization of an occupational stress index Agra psychological lab.

[21] Singh, K. and Billingsley, B.S. (1996). Intent to Stay in Teaching: Teachers of Students with Emotional Disorders Versus Other Special Eductors. Remedial and Special Education, 17 (1), 37-47.

[22] Travers, C. \& Cooper, C. (1996). Teachers under pressure: stress in the teaching profession. London: Routledge.

\section{Volume 6 Issue 12, December 2017}

